Rev. Adm. Saúde (On-line), São Paulo, v. 20, n. 80: e250, jul. - set. 2020, Epub 30 set. 2020 http://dx.doi.org/10.23973/ras.80.250

ARTIGO ORIGINAL

\title{
Taxa de mortalidade infantil no Piauí e determinantes sociais
}

Infant mortality rate in Piaui and social determinants

\section{Djalma Ribeiro Costa ${ }^{1}$, Alexandre Gabriel Silva Rego², Lucas Guilherme Mota de Sousa ${ }^{3}$, Bruno Pinheiro Falcão ${ }^{4}$}

1. Médico especialista em medicina preventiva e social. Médico do Hospital Infantil Lucídio Portella, Teresina, Piauí.

2. Médico do Programa Saúde da Família. Fundação Municipal de Saúde de Teresina, Piauí.

3. Médico generalista. Médico da Secretaria Estadual de Saúde do Piauí, Teresina, Piauí.

4. Médico especialista em cirurgia pediátrica. Maternidade Dona Evangelina Rosa, Teresina, Piauí

\section{RESUMO}

Introdução: a taxa de mortalidade infantil é um indicador sensível às transformações sociais de uma região, sinaliza o desenvolvimento socioeconômico e as condições de vida, importando, por isso, aos profissionais da administração em saúde e da medicina preventiva e social. Objetivos: estabelecer a associação entre determinantes sociais e a taxa de mortalidade infantil nos municípios do Piauí em 2010. Metodologia: estudo ecológico de correlação e autocorrelação espacial entre a taxa de mortalidade infantil e os indicadores índice de desenvolvimento humano municipal e seus componentes longevidade, renda e emprego e educação, coeficiente de Gini e proporção de pobres em 2010. Os dados foram obtidos no sítio eletrônico do Atlas de Desenvolvimento Humano no Brasil. Realizou-se estatística descritiva, teste de correlação de Spearman e dependência espacial univariada e bivariada com o 
índice de Moran. Consideraram-se estatisticamente significante um valor $p$ menor de 0,05 e um pseudo-p menor ou igual a 0,05 quando o módulo do valor $\mathrm{z}$ fosse maior ou igual a 1,96 . Utilizaram-se os softwares MINITAB v.17, GeoDa e R Studio. Este trabalho foi aprovado pelo CEP da Universidade Federal do Piauí. Resultados: A taxa de mortalidade infantil correlacionou-se de modo complexo e nem sempre homogêneo com o IDHM, com os componentes do IDHM e com a proporção de pobres. Não houve correlação com o coeficiente de Gini. O IDHM renda e emprego foi o único determinante social que não exibiu dependência espacial. Apenas o IDHM longevidade correlacionou-se espacialmente com a taxa de mortalidade infantil, predominando a formação de outliers onde maior IDHM longevidade esteve associado com menor mortalidade infantil. Conclusões: Existiram correlação e autocorrelação espacial entre taxa de mortalidade infantil e determinantes sociais no Piauí em 2010. As áreas de maior risco, principalmente aquelas com piores indicadores sociais, são alvo das ações de planejamento estratégico em administração em saúde e em medicina preventiva e Social.

Palavras-chave: Mortalidade Infantil. Determinantes Sociais da Saúde. Correlação de Dados. Análise Espacial.

\section{ABSTRACT}

Introduction: infant mortality rate is a sensitive indicator to regional social transformations and indicates the socioeconomic development and the way of life, consequently it matters to health administration and to preventive and social medicine. Objectives: to establish the association between social determinants and the infant mortality rate in the cities of Piaui in 2010. Methodology: ecological study of correlation and spatial autocorrelation between the infant mortality rate and the human development index and their components ('longevity', 'income and employment' and 'education'), Gini's coefficient and proportion of poverty in 2010. Data were obtained from the website of Atlas of Human Development in Brazil. Descriptive statistics, Spearman's correlation test and univariate and bivariate spatial dependence with the Moran index were performed. A p-value less than 0.05 and a pseudo-p equals to or less than 0.05 with an absolute $z$-value equals to or greater than 1.96 were considered statistically significant. The software MINITAB v.17, GeoDa and R Studio were used. This paper was approved by the Research Ethics Committee of the Federal University of Piaui. Results: The infant mortality rate correlated in a complex and not always homogeneous way with the $\mathrm{HDI}$, with the components of the $\mathrm{HDI}$ and with the proportion of poverty. There was no correlation with the Gini's coefficient. The income and employment component of HDI was the only social determinant that did not demonstrate spatial dependence. Only the longevity component of HDI was spatially correlated with the infant mortality rate, with the formation of outliers predominating where greater longevity component of HDI was associated with lower infant mortality rate. Conclusions: There were correlation and spatial autocorrelation between infant mortality rate and social determinants in Piaui in 2010. The areas of greatest risk, especially those with the worst social 
determinants, are the target of strategic planning actions in health administration and preventive and social medicine.

Keywords: Infant Mortality. Social Determinants of Health. Correlation of Data. Spatial Analysis.

\section{INTRODUÇÃO}

A taxa de mortalidade infantil é, entre os diversos indicadores sanitários, um dos mais sensíveis às transformações sociais de uma região. Por isso, ela reflete as condições de desenvolvimento socioeconômico e infraestrutura ambiental, além da acessibilidade e qualidade dos serviços de saúde às mães e à população infantil. É utilizado para análises demográficas, espaciais e temporais da mortalidade infantil as quais são úteis em estudos voltados para a redução de iniquidades sociais, estudos de tendência, estudos comparativos e é instrumento de controle útil para o planejamento estratégico em saúde ${ }^{1,2}$.

A mortalidade infantil segue sendo um problema real por todo o globo e sua redução é um dos Objetivos de Desenvolvimento do Milênio, porquanto existe assimetria espacial deste indicador entre os países, evidenciando que os avanços em medicina preventiva e social e em administração em saúde que ocorreram desde a revolução industrial não foram bastantes para assegurar qualidade de acessibilidade e cuidados em saúde pública por questões ambientais, culturais, geopolíticas, demográficas, epidemiológicas, políticas e financeiras ${ }^{3}$.

Segundo o Instituto Brasileiro de Geografia e Estatística (IBGE), nos últimos dois censos demográficos houve redução da taxa de mortalidade infantil no país e nas regiões, inclusive no Nordeste onde as iniquidades sociais são sabidamente responsáveis pelas taxas desfavoráveis de óbitos evitáveis ${ }^{3}$.

A redução de fatores adversos externos como as condições ambientais, qualidade habitacional, saneamento básico e escolaridade das mães são motivos da redução das taxas de mortalidade infantil no mundo. São desse modo objetos da medicina preventiva porquanto agem na etapa pré-patogênica de Leavell e Clarck ${ }^{4,5}$. Segundo a Organização Mundial de Saúde, políticas públicas que agem nas etapas mais precoces do processo de adoecimento são muito mais eficazes, efetivas e eficientes ${ }^{3,6-9}$.

O conhecimento da associação dos problemas de saúde com determinantes sociais bem como a identificação espacial de áreas estratégicas representam informação útil para o planejamento estratégico em saúde, interessando aos gestores de saúde pública e aos pesquisadores em medicina social, uma vez que a administração de custos, financeira e orçamentária pautar-se-ia em 
evidência científica, evitando gastos desnecessários e favorecendo a saúde coletiva equitativa que prioriza grupos populacionais sob ${ }^{6,10-13}$.

Nesse sentido, intervenções sobre toda a população são caras para implementar e, frequentemente, urge-se direcionar esses investimentos a áreas estratégicas. Investigar espacialmente determinantes de desfechos adversos em saúde auxilia os gestores a intervir de modo focado e custo-efetivo ${ }^{14}$. Diante disso, este trabalho buscou conhecer a correlação e a autocorrelação espacial entre a taxa de mortalidade infantil e os determinantes sociais referentes ao coeficiente de Gini, o índice de desenvolvimento humano municipal e seus componentes longevidade, educação e renda e emprego bem como com a proporção de pobres no ano de 2010 no municípios piauienses.

\section{METODOLOGIA}

Estudo ecológico sobre a taxa de mortalidade infantil e sua associação com o índice de desenvolvimento humano municipal (IDHM) e com seus componentes longevidade (IDHM longevidade), educação (IDHM educação) e renda e emprego (IDHM renda e emprego, com o coeficiente de Gini e com a proporção de pobres, doravante denominados determinantes sociais. Realizou-se estudo de análise espacial sobre esses indicadores relativos ao ano 2010.

A área de estudo foi o Piauí e seus 224 municípios. O Piauí é uma unidade federativa localizada no noroeste da Região Nordeste do Brasil. Faz fronteira a leste com Ceará e com Pernambuco, a sul e sudeste com a Bahia, a sudoeste com Tocantins e a oeste com Maranhão. Delimita-se a norte com o Oceano Atlântico. Sua capital é Teresina (Figura 1).

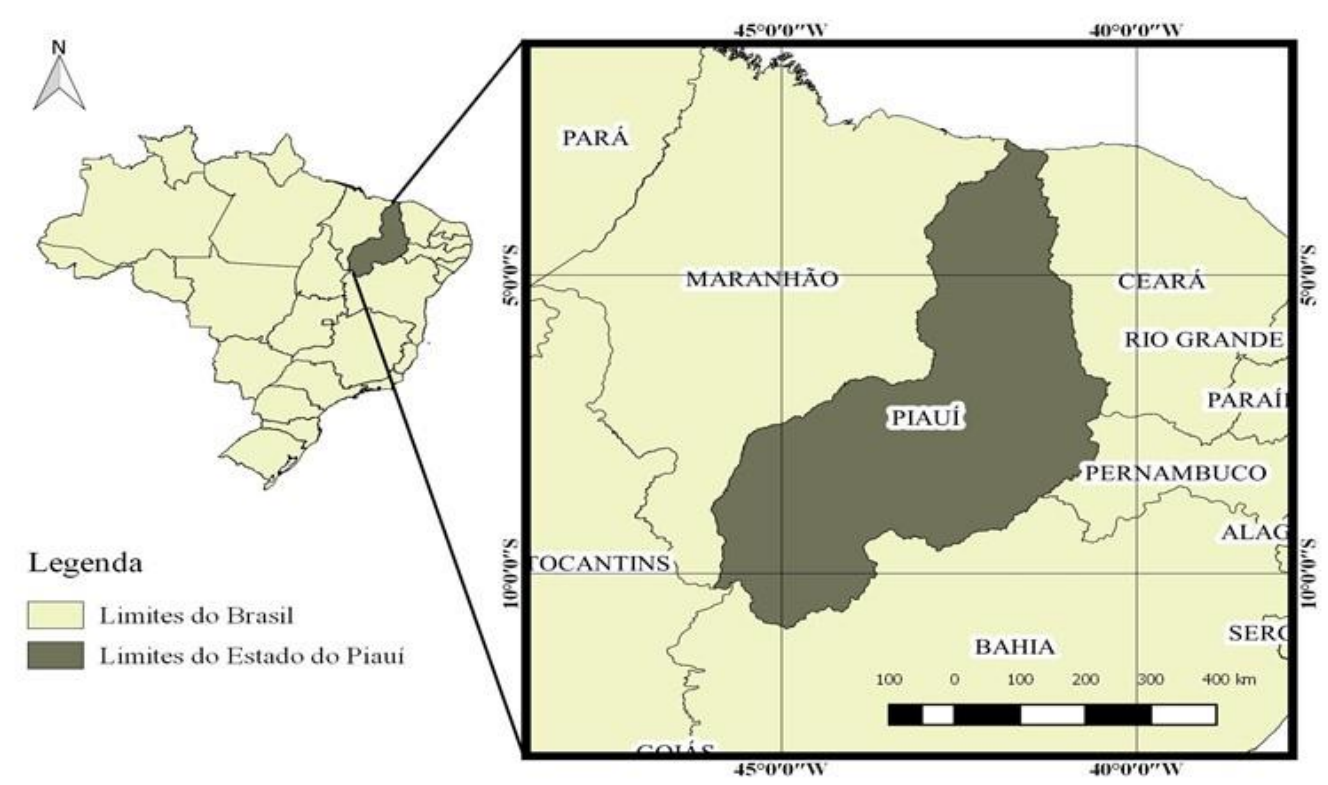

Figura 1. Mapa da área de estudo, Piauí, 2019. Fonte: IBGE (2019). 
Os dados deste estudo são do tipo secundário. A fonte desses dados foi o Atlas do Desenvolvimento Humano no Brasil

(http://www.atlasbrasil.org.br/2013/). Nesse sítio eletrônico, foram obtidos os vetores correspondentes à taxa de mortalidade infantil (óbitos de menores de um ano por 1000 nascidos vivos, simbolizado por \%o), o coeficiente de Gini, a proporção de pobres (\%) e o IDHM e seus componentes para cada município piauiense no ano 2010.

O coeficiente ou índice de Gini mede o grau de desigualdade existente na distribuição de indivíduos segundo a renda domiciliar per capita. Seu valor 0 indica ausência de desigualdade, ou seja, a renda domiciliar per capita de todos os indivíduos têm o mesmo valor. Seu valor máximo é 1. Quanto mais próximo de 1, maior a desigualdade. Este coeficiente é calculado sobre a população com domicílio particular permanente ${ }^{15,16}$.

Proporção de pobres consiste na proporção de indivíduos com renda domiciliar per capita igual ou inferior a $R \$ 140,00$ mensais em agosto de 2010. Este indicador é calculado sobre a população com domicílio particular permanente 17.

O IDHM é um indicador que permite conhecer a realidade do desenvolvimento humano além das condições econômicas e consiste na média geométrica de três componentes: IDHM longevidade, IDHM educação e IDHM renda e emprego. IDHM é calculado tendo como base a expectativa de vida ao nascer, logo, quanto melhores as condições de saúde da população tanto maior o IDHM longevidade (IDHMlong). O IDHM renda e emprego (IDHMre) é calculado sobre a renda per capita. O IDHM educação (IDHMeduc) é uma média geométrica de dois outros indicadores: escolaridade da população adulta e fluxo escolar da população jovem. O IDHM é classificado em muito baixo $(0 \mathrm{a}$ $0,499)$, baixo $(0,5$ a 0,599$)$, médio $(0,6$ a 0,699$)$, alto $(0,7$ a 0,799$)$ e muito alto $(0,8 \text { a } 1)^{18,19}$.

O protocolo analítico está resumido na Figura 2. 


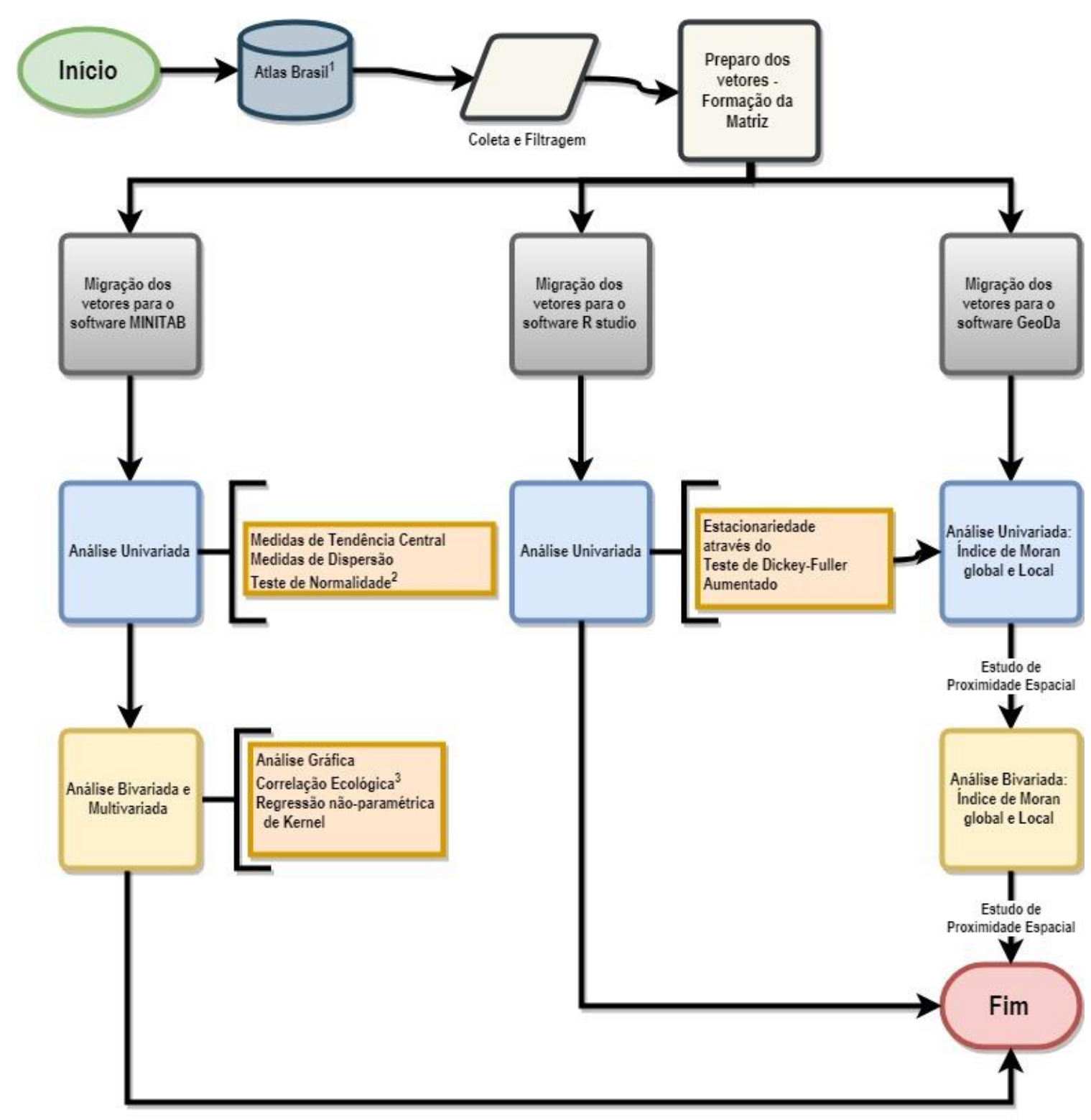

Figura 2. Protocolo descritivo e analítico do estudo.

${ }^{1}$ Atlas do Desenvolvimento Humano no Brasil. ${ }^{2}$ Teste de Anderson-Darling. ${ }^{3}$ Correlação de Spearman.

A taxa de mortalidade infantil foi classificada em baixa, média e alta quando seus valores são, respectivamente, menores de $20 \%, 20 \%$ a $49 \%$ e $50 \%$ conforme a Rede Interagencial de Informações para a Saúde (RIPSA) ${ }^{1}$. Essa classificação foi utilizada na análise gráfica bivariada dos determinantes sociais segundo a classificação da taxa de mortalidade. Nesse momento, todas as variáveis foram normalizadas segundo a Equação 1, porquanto a maioria dos vetores não apresentaram distribuição normal, esta técnica imprime valores de 0 a 1 e permitiu melhor visualização das relações intervetoriais. 


$$
\text { Vetor Normalizado }=\frac{\text { Observação }- \text { valor mínimo }}{\text { Valor máximo }- \text { valor mínimo }}
$$

Equação 1. Método de normalização de vetores.

Uma vez normalizados, realizaram-se as análises bivariadas através do teste de correlação de Spearman somada a interpretação qualitativa do coeficiente Rhô e da monotonicidade da reta da regressão não paramétrica de Kernel (suavização 0,5 e Etapas 2) segundo Owen (Figura 3). Segundo este, Rhô pode ser positivo indicando relação diretamente proporcional entre os vetores ou negativa, indicando o contrário. Além disso, se seu valor não for estatisticamente significante ou for igual a zero, significa não haver autocorrelação, se maior de zero até 0,19 , diz muito fraca correlação. De 0,2 a 0,39, fraca, de 0,4 a 0,59, moderada, de 0,60 a 0,79, forte, e de 0,80 a 1,0, muito forte correlação. A monotonicidade, quando presente, indica correlação sempre positiva ou negativa entre os vetores. Sua ausência sugere relação complexa entre os vetores ou correlação ausente ${ }^{20}$.

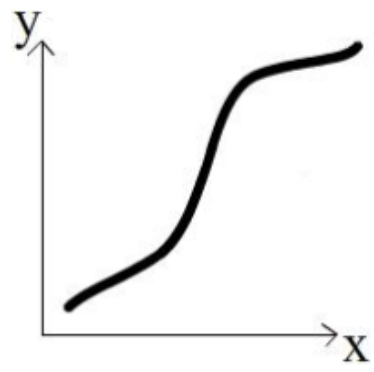

Monotonicamente crescente

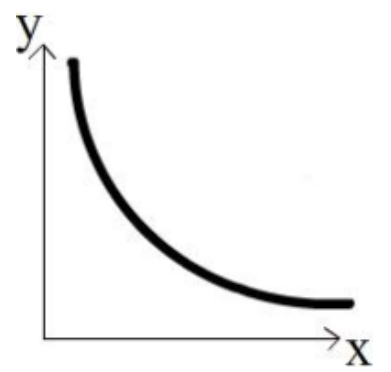

Monotonicamente decrescente

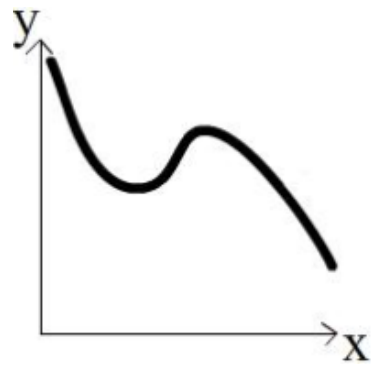

Não monotônica

Figura 3. Monotonicidade da reta de associação entre dois vetores. Fonte: Owen (2020).

Proximidade espacial foi expressa por pontos cardeais (norte, sul, leste e oeste), subcardeais (nordeste, sudeste, noroeste e sudoeste) e limites do estado (litoral, Ceará, Pernambuco, Bahia, Tocantins e Maranhão), tomando por referência a Figura 1 e a rosa dos ventos.

O estudo de dependência espacial foi realizado através do índice de Moran global e local. O índice de Moran é uma taxa de autocorrelação. Sua hipótese intrínseca é a estacionariedade dos dados do vetor em lag $=1$ e lag $=2^{21}$. Os 
vetores incluídos no modelo foram a taxa de mortalidade infantil e os determinantes sociais. Realizou-se o teste de Dickey-Fuller Aumentado do pacote tseries sob o comando adf.test $(\mathrm{y}, \mathrm{k}=1)$ e adf.test $(\mathrm{y}, \mathrm{k}=2)$, onde y foi $\mathrm{o}$ vetor testado e $k=1$ significa lag=1 e $k=2$ significa lag=2 ${ }^{22}$ no software $R$ Studio 22,23 .

O índice I de Moran foca em valores de pares de regiões vizinhas. É calculado conforme a Equação 2, em que há $n$ regiões e $w_{i j}$ é o peso descrevendo a relação entre as regiões $i$ e $j$.

$$
I=\frac{n \sum_{i=1}^{n} \sum_{j=1}^{n} w_{i j}\left(x_{i}-\bar{x}\right)\left(x_{j}-\bar{x}\right)}{\left(\sum_{i=1}^{n} \sum_{j=1}^{n} w_{i j}\right) \sum_{i=1}^{n}\left(x_{i}-\bar{x}\right)^{2}}
$$

Equação 2. Equação do índice de Moran.

Assim, se as regiões são adjacentes do tipo rainha num tabuleiro de xadrez, então $w_{i j}$ é igual a 1, pois tanto as fronteiras quanto os vértices são considerados contíguos na visualização de um mapa. Caso contrário, $w_{i j}$ é zero ${ }^{24}$ (Figura 4).

\begin{tabular}{|c|c|c|c|c|c|c|}
\hline $\mathrm{A}_{-}$ & $\mathrm{B}$ & Cي & & $j$ & $j$ & ${ }^{j}$ \\
\hline $\mathrm{D} 4$ & - & $\rightarrow \mathrm{F}$ & $\longrightarrow$ & $j$ & $i$ & $j$ \\
\hline $\mathrm{G}^{2}$ & $\stackrel{t}{H}$ & I & & $j$ & $j$ & $j$ \\
\hline
\end{tabular}

Figura 4. Matriz de contiguidade do tipo rainha. Fonte: Almeida (2012).

O resultado da análise local do índice de Moran são observações similares (Alta-Alta e Baixa-Baixa) e dissimilares (Baixa-Alta e Alta-Baixa). Observações similares ou clusters estabelecem relação diretamente proporcional entre a variável no eixo x e a variável no eixo y. Observações dissimilares, atípicas ou outliers estabelecem relação inversamente proporcional entre variável no eixo $x$ e variável no eixo $\mathrm{y}^{25}$. Neste estudo, a variável no eixo $\mathrm{x}$ foi a taxa de mortalidade infantil na análise univariada ou os determinantes sociais na análise bivariada. A variável no eixo y foi a taxa de mortalidade infantil defasada. 
Valores positivos e estatisticamente significantes (valor $z \geq+1,96$ ) do índice de Moran tendendo $\mathrm{a}+1$ indicam que houve aglomeração (ou clustered). Valores negativos e estatisticamente significantes (valor $z \leq-1,96$ ) evidenciam dispersão (ou dispersed). Valores nulos ou que não são estatisticamente significantes sinalizam para distribuição espacial aleatória (random) ${ }^{21}$ (Figura $5)$.
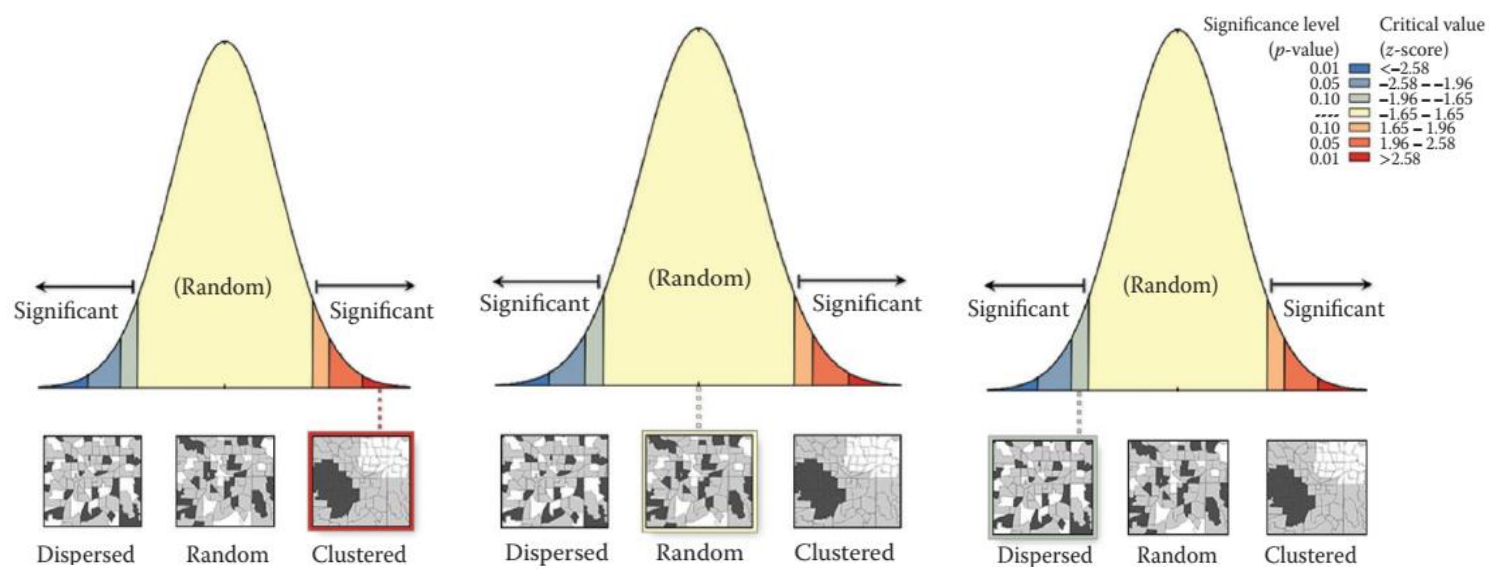

Figura 5. Padrões de dependência espacial.

Dispersed: disperso; random: aleatório; clustered: aglomerado; significance level: nível de significância; critical value: valor crítico; $p$-value: valor $p$ (ou pseudo-p). Fonte: Oyana (2016).

O resultado do teste global neste estudo foi representado na forma de tabela com valor I, esperança $(E)$, média $(\mu)$ e desvio-padrão $(\sigma)$, valor z e pseudo-p apresentados na forma de tabela tanto na análise univariada quanto na bivariada. A força de dependência espacial foi apresentada na forma de distância do valor I da média em termos de desvios-padrões.

Uma vez existindo dependência espacial (módulo do valor $z \geq 1,96$ ), realizaram-se as análises locais representadas neste trabalho na forma de mapas categorizados com os clusters Alta-Alta, Baixa-Baixa e seus outliers Baixa-Alta e Alta-Baixa. Utilizaram-se de modo complementar mapas coropléticos de valor de pseudo-p em escala de cor verde.

Dependência espacial univariada indicou onde a taxa de mortalidade infantil foi espacialmente dependente. A dependência espacial bivariada indicou a dependência espacial entre determinante social e taxas de mortalidade infantil $21,26,27$.

As análises espaciais foram feitas no software GeoDa 1.14.0. Estatísticas descritivas e analíticas não espaciais foram feitas no MINITAB v.17 e no $R$ Studio. Considerou-se estatisticamente significante um pseudo-p menor ou igual a 0,05 se o módulo do valor $z$ tiver sido maior ou igual a 1,96 e um valor $p$ 
menor de 0,05. Este trabalho foi aprovado pelo comitê de ética em pesquisa da Universidade Federal do Piauí sob o parecer no 2.975.846.

\section{RESULTADOS}

A taxa de mortalidade infantil variou de $16,1 \%$ a $41,5 \%$ nos 224 municípios piauienses em 2010. Ocorreu, em média, 28 óbitos em menores de um ano de idade para cada 100 nascimentos. O índice de Gini foi, em média, 0,545, indicando desigualdade média na distribuição da renda nos 224 municípios de $54,5 \%$. O IDHM médio foi 0,571 , sinalizando desenvolvimento humano municipal baixo. De modo global, o desempenho municipal quanto ao IDHM longevidade foi superior ao IDHM renda e emprego e ao IDHM educação. A média municipal da proporção de pobres foi 45,72\% (Tabela 1).

Tabela 1. Taxa de mortalidade infantil e determinantes sociais no Piauí, 2010. Fonte: Atlas Brasil (2020); DATASUS (2020).

\begin{tabular}{|c|c|c|c|c|c|c|c|}
\hline Variável & Média & $\begin{array}{l}\text { Desvio- } \\
\text { Padrão }\end{array}$ & Mínimo & Máximo & Mediana & $\begin{array}{r}\text { Amplitude } \\
\text { Interquartílica }\end{array}$ & $\begin{array}{r}\text { Valor } \\
p^{2}\end{array}$ \\
\hline TMI $(x 1000)^{b}$ & 28,23 & 5,29 & 16,1 & 41,5 & 27,2 & 8 & $<0,001$ \\
\hline Gini & 0,545 & 0,04 & 0,431 & 0,797 & 0,539 & 0,059 & 0,021 \\
\hline IDHM $^{\mathrm{c}}$ & 0,571 & 0,04 & 0,485 & 0,751 & 0,565 & 0,044 & $<0,001$ \\
\hline IDHM R\&E ${ }^{d}$ & 0,546 & 0,04 & 0,462 & 0,731 & 0,539 & 0,048 & $<0,001$ \\
\hline $\begin{array}{l}\text { IDHM } \\
\text { longevidade }\end{array}$ & 0,749 & 0,02 & 0,685 & 0,820 & 0,753 & 0,043 & $<0,001$ \\
\hline $\begin{array}{l}\text { IDHM } \\
\text { educação }\end{array}$ & 0,456 & 0,06 & 0,315 & 0,707 & 0,451 & 0,077 & 0,144 \\
\hline$\%$ Pobres $^{e}$ & 45,72 & 9,45 & 14,6 & 65,37 & 46,27 & 13,2 & 0,248 \\
\hline
\end{tabular}

a Teste de Anderson Darling (valor $p>0,05$ sinaliza distribuição normal). ${ }^{b}$ Taxa de mortalidade infantil. c Índice de desenvolvimento humano. ${ }^{d}$ Renda e emprego. e Proporção de pobres.

A taxa de mortalidade infantil apresentou menores coeficientes com maiores valores de IDHM, IDHM longevidade, IDHM educação e IDHM renda e emprego. Houve associação paradoxal entre coeficiente de Gini com a taxa de mortalidade infantil. A proporção de pobres foi maior no grupo de taxa de mortalidade infantil entre $20 \%$ e $49 \%$ (Figura 6). 


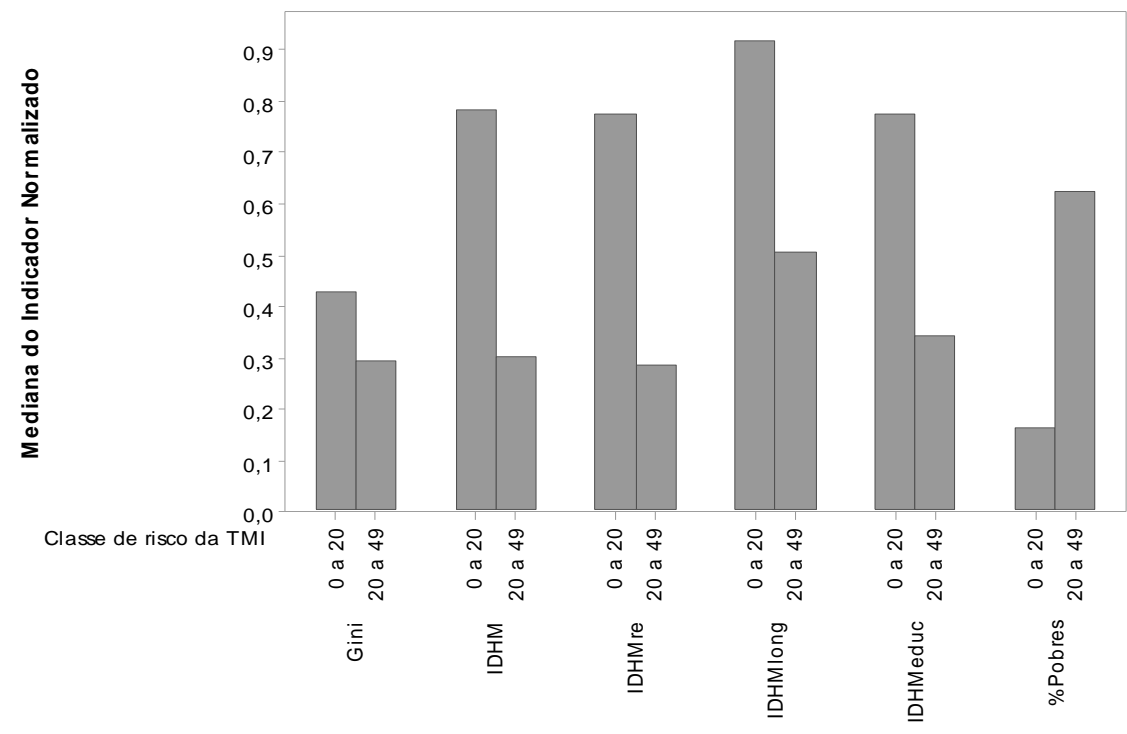

Figura 6. Determinantes sociais segundo a classificação da taxa de mortalidade infantil no Piauí, 2010. Fonte: Atlas Brasil (2020).

TMI: taxa de mortalidade infantil; IDHM: índice de desenvolvimento infantil; re: renda e emprego; long: longevidade; educ: educação; e \%Pobres: proporção de pobres. As variáveis foram normalizadas. De 0 a $20 \%$ indica baixa taxa e de $20 \%$ a $49 \%$ indica média taxa de mortalidade infantil.

Não houve correlação ecológica entre a taxa de mortalidade infantil e o coeficiente de Gini. Houve correlação ecológica muito fraca e positiva com a proporção de pobres. A correlação foi negativa e significante com IDHM e seus componentes (Tabela 2).

Tabela 2. Correlação ecológica entre determinantes sociais e a taxa de mortalidade infantil no Piauí, 2010. Fonte: Atlas Brasil (2020).

Determinante Social

Rhô de Valor-p Interpretação qualitativa Spearman

\begin{tabular}{lrrl}
\hline Gini & $-0,055$ & 0,416 & Sem correlação \\
IDHM & $-0,463$ & $<0,001$ & $\begin{array}{l}\text { Moderada correlação } \\
\text { negativa }\end{array}$ \\
$\begin{array}{llll}\text { IDHM renda e emprego } & -0,206 & 0,002 & \text { Fraca correlação negativa } \\
\text { IDHM longevidade } & -0,998 & 0,002 & \begin{array}{l}\text { Muito forte correlação } \\
\text { negativa }\end{array} \\
\text { IDHM educação } & -0,315 & <0,001 & \text { Fraca correlação negativa } \\
\text { Proporção de Pobres } & 0,196 & 0,003 & \text { Muito fraca correlação }\end{array}$ \\
\hline
\end{tabular}


A falta de monotonicidade das curvas de suavização pode justificar a fraqueza de correlação apresentadas na Tabela 2. Nas curvas mais lineares, houve maior correlação. Observou-se na curva de suavização, um ponto crítico de 0,5 nos valores normalizados para IDHM renda e emprego e proporção de pobres. Ausência de regressão antes desse valor para o IDHM renda e emprego e depois desse valor para proporção de pobres. As curvas são predominantemente monotônicas para IDHM, IDHM longevidade e IDHM educação. Evidenciou-se concordância gráfico-semântica entre as classes do IDHM com taxa de mortalidade infantil, componentes longevidade, educação, renda e emprego e proporção de pobres (Figura 7).

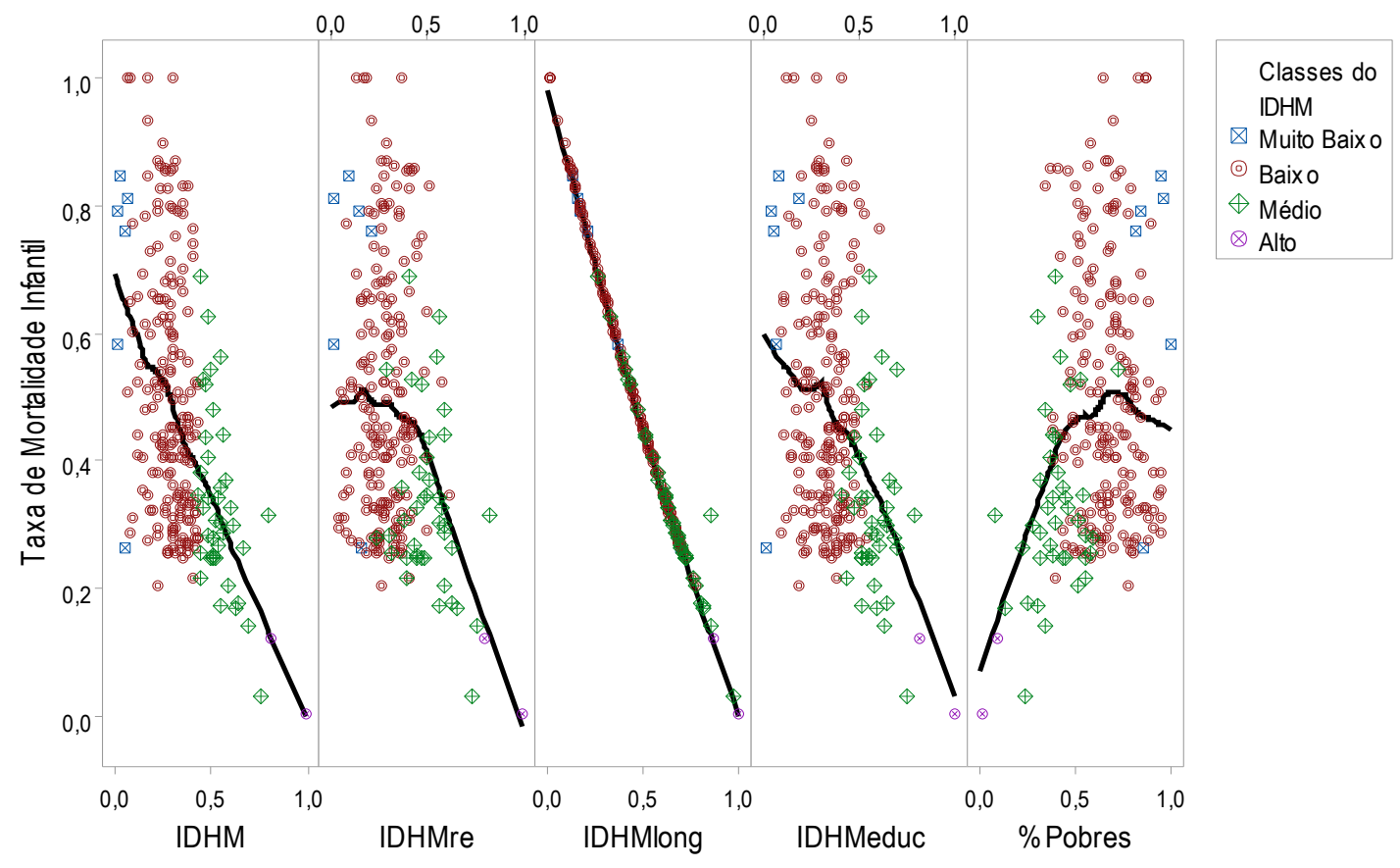

Figura 7. Associação entre taxa de mortalidade infantil, os determinantes sociais e classes do índice de desenvolvimento humano municipal no Piauí, 2010. Fonte: Atlas Brasil (2020).

TMI: taxa de mortalidade infantil; IDHM: índice de desenvolvimento infantil; re: renda e emprego; long: longevidade; educ: educação; \%Pobres: proporção de pobres. Todas as variáveis estão normalizadas.

Os vetores foram estacionários em lag=1 e lag=2. Coeficiente de Gini, IDHM e seus componentes longevidade e educação e proporção de pobres apresentaram dependência espacial estatisticamente significante através do índice de Moran global. Eles apresentaram índice I positivo que distou entre $2,79 \sigma$ a $5 \sigma$ à direita da média $\mu(I)$, indicando significante dependência espacial. 
O tipo de dependência espacial observado foi a formação de aglomerados (valor $z \geq+1,96$ ) (Tabela 3).

Tabela 3. Dependência espacial univariada da taxa de mortalidade infantil e dos vetores correspondentes aos indicadores. Piauí, 2010. Fonte: Atlas Brasil (2020).

\begin{tabular}{|c|c|c|c|c|c|c|c|c|c|}
\hline \multirow[t]{2}{*}{ Vetores } & \multicolumn{2}{|c|}{$\begin{array}{r}\text { Teste de } \\
\text { Dickey-Fuller } \\
\text { Aumentado }^{\mathrm{a}}\end{array}$} & \multirow[b]{2}{*}{ I } & \multirow[b]{2}{*}{$E[I]$} & \multirow[b]{2}{*}{$\mu(I)$} & \multicolumn{3}{|c|}{ Índice de Moran Global } & \multirow{2}{*}{$\begin{array}{l}\text { Elegível } \\
\text { ao índice } \\
\text { de Moran } \\
\text { local e ao } \\
\text { modelo } \\
\text { bivariado }\end{array}$} \\
\hline & $\begin{array}{r}\text { Valor } \\
p^{b}\end{array}$ & $\begin{array}{r}\text { Valor } \\
p^{c}\end{array}$ & & & & $\sigma(\mathrm{I})$ & $\begin{array}{r}\text { Valor } \\
\mathrm{z}\end{array}$ & $\begin{array}{l}\text { Pseudo } \\
\text { valor-p }\end{array}$ & \\
\hline $\begin{array}{l}\text { TMI } \\
(\times 1000)\end{array}$ & 0,01 & 0,01 & 0,1178 & $\begin{array}{r}- \\
0,0045\end{array}$ & 0,006 & 0,0411 & 3,01 & 0,005 & Sim \\
\hline Gini & 0,01 & 0,01 & 0,2042 & 0,0045 & 0,004 & 0,0407 & 5,11 & 0,001 & Sim \\
\hline IDHM & 0,01 & 0,01 & 0,1334 & 0,0045 & $0,004^{-}$ & 0,0424 & 3,25 & 0,001 & Sim \\
\hline IDHMre & 0,01 & 0,01 & 0,0333 & 0,0045 & 0,003 & 0,0416 & 0,88 & 0,19 & Não \\
\hline IDHMlong & 0,01 & 0,01 & 0,1143 & 0,0045 & 0,006 & 0,0409 & 2,93 & 0,005 & Sim \\
\hline IDHMeduc & 0,01 & 0,01 & 0,2028 & 0,0045 & 0,004 & 0,0427 & 4,84 & 0,001 & Sim \\
\hline$\%$ Pobres & 0,01 & 0,01 & 0,1780 & $\begin{array}{r}- \\
0,0045\end{array}$ & 0,003 & 0,0417 & 4,34 & 0,001 & Sim \\
\hline
\end{tabular}

${ }^{\mathrm{a} E s t a c i o n a r i e d a d e ~ s e ~ v a l o r ~} \mathrm{p}<0,05$; ${ }^{\mathrm{b} l a g}=1$; ${ }^{\mathrm{clag}}=2$.

TMI: taxa de mortalidade infantil; IDHM: índice de desenvolvimento infantil; re: renda e emprego; long: longevidade; educ: educação; \%Pobres: proporção de pobres.

Aglomerado de municípios com alta taxa de mortalidade infantil com dependência espacial ocorreu no sudeste do Estado na fronteira com Pernambuco conforme Figura 1 (valor de pseudo- $p \leq 0,05$ ). Neles, a taxa de mortalidade variou de $29 \%$ a $41,5 \%$, o coeficiente de Gini variou de 0,482 a 0,604 , o IDHM variou de 0,489 a 0,588 e a proporção de pobres variou de $37,41 \%$ a $62,59 \%$. Esses achados sinalizam para aglomeração de municípios com importante desigualdade de renda familiar, com baixo desenvolvimento humano e significante proporção de pobres. Esse aglomerado inclui os municípios Belém do Piauí, Betânia do Piauí, Caldeirão Grande do Piauí, Campo Grande do Piauí, Francisco Macedo, Massapê do Piauí, Padre Marcos e Vila Nova do Piauí (Figura 8). 
Aglomerados de municípios com baixos valores de mortalidade infantil com dependência espacial ocorreram no centro-norte, no noroeste e sudoeste do Estado na fronteira com o Maranhão e ao sul na fronteira com a Bahia conforme Figura 1. Neles, a taxa de mortalidade variou de $16,13 \%$ a $26,9 \%$, o coeficiente de Gini variou de 0,470 a 0,617, o IDHM variou de 0,508 a 0,751 (baixo a alto desenvolvimento humano) e a proporção de pobres variou de $14,6 \%$ a $62,15 \%$. Incluem os municípios Altos, Batalha, Beneditinos, Capitão de Campos, Cocal de Telha, Cristalândia do Piauí, Curralinhos, Demerval Lobão, Jatobá do Piauí, José de Freitas, Milton Brandão, Monsenhor Gil, Nazária, Palmeirais, Ribeiro Gonçalves, Sebastião Barros e Teresina (a capital) (Figura 8).

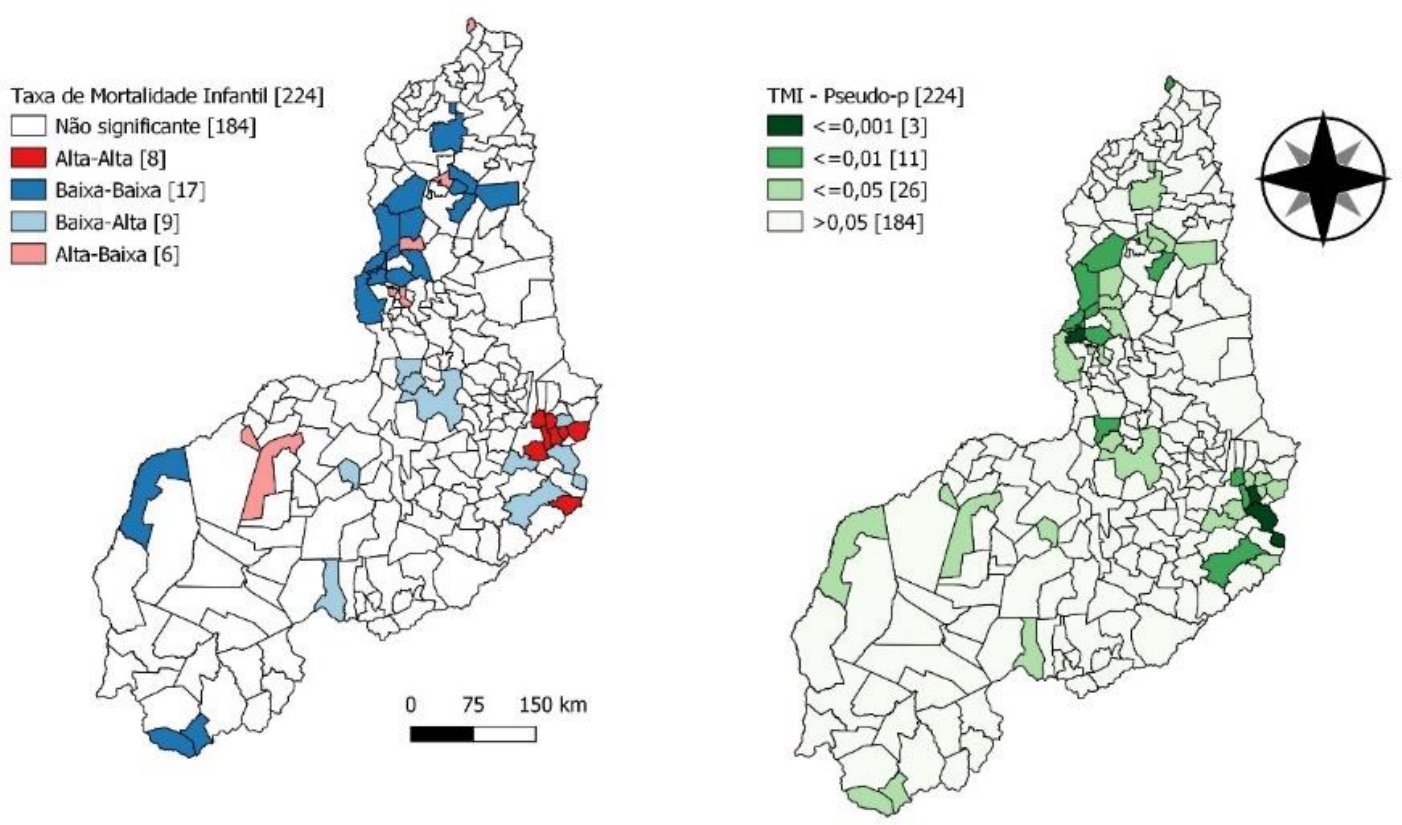

Figura 8. Dependência espacial da taxa de mortalidade infantil no Piauí, 2010. Fonte: Atlas Brasil (2020).

A aglomeração de municípios com elevado coeficiente de Gini no sul, sudeste e sudoeste do Estado, nas fronteiras com a Bahia, Pernambuco e Maranhão (Figura 9). A ausência de concordância espacial entre aglomerados de municípios com elevado coeficiente de Gini e os aglomerados com alta taxa de mortalidade infantil pode justificar a relação paradoxal observada na Figura 4 e a ausência de correlação ecológica na Tabela 2. 

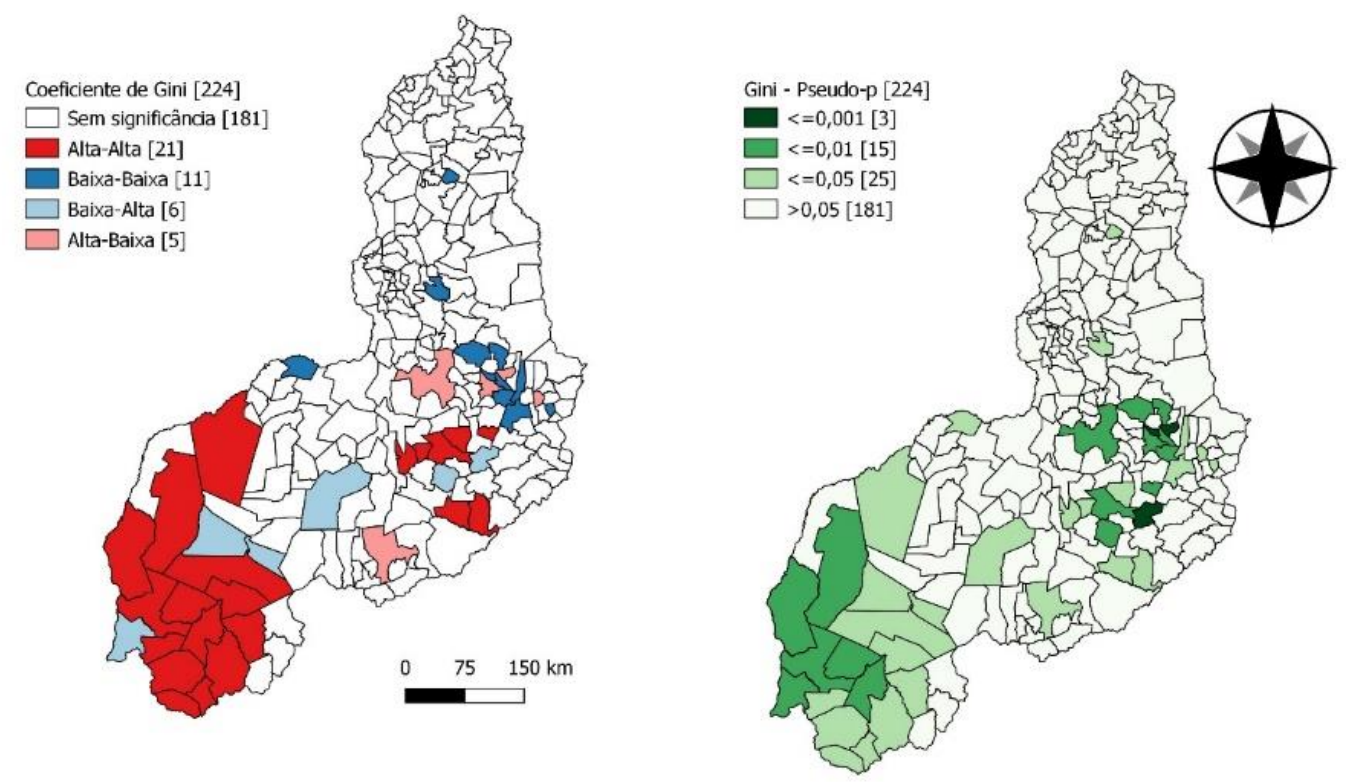

Figura 9. Dependência espacial do coeficiente de Gini no Piauí, 2010. Fonte: Atlas Brasil (2020).

Observou-se concordância espacial entre IDHM e taxa de mortalidade infantil pelo índice de Moran local, de modo que municípios com elevado IDHM situaram-se predominantemente a noroeste, onde houve menor taxa de mortalidade. Houve municípios com baixo IDHM no sudeste e norte do Estado (pseudo-p $\leq 0,05)$ (Figura 10). 

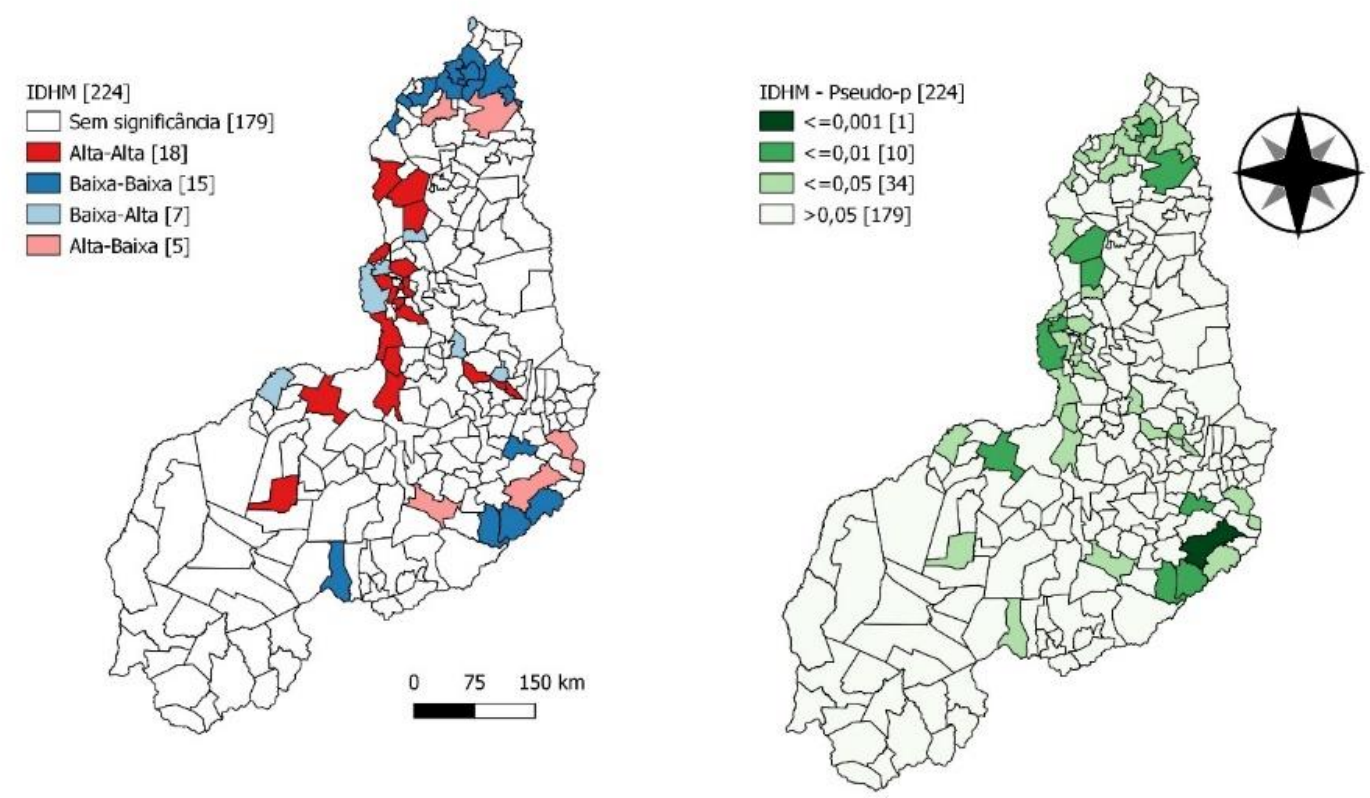

Figura 10. Dependência espacial do índice de desenvolvimento humano municipal no Piauí, 2010. Fonte: Atlas Brasil (2020).

Igualmente houve concordância espacial gráfica entre IDHM longevidade e taxa de mortalidade infantil, de modo que municípios com elevado IDHM longevidade situaram-se a noroeste, centro-norte, sudoeste e sul nos limites com os Estados do Maranhão e Bahia e municípios com baixo IDHM longevidade situaram-se no sudeste do Estado na fronteira com Pernambuco (pseudo-p $\leq 0,05)$ (Figura 11). 

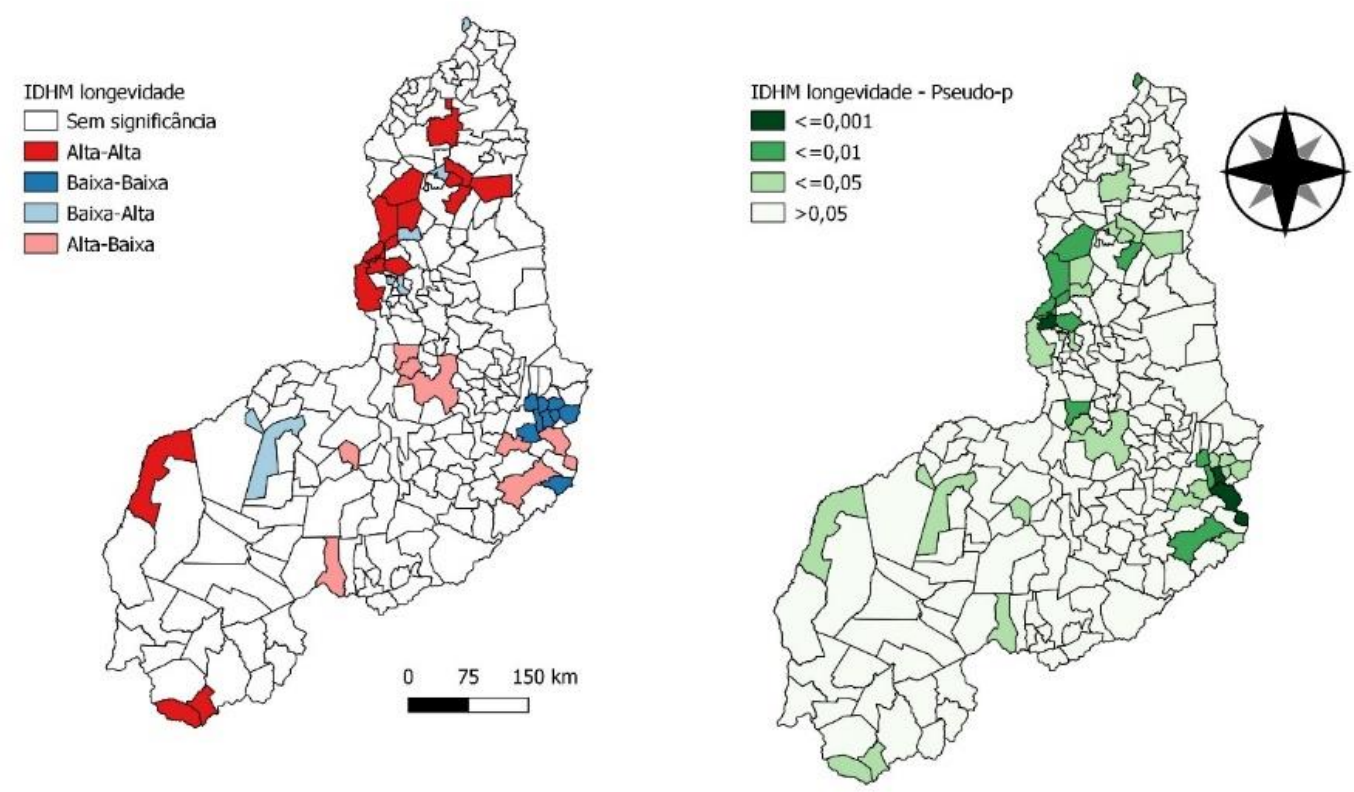

Figura 11. Dependência espacial do componente longevidade do índice de desenvolvimento humano municipal no Piauí, 2010. Fonte: Atlas Brasil (2020).

Observou-se concordância espacial gráfica entre IDHM educação e taxa de mortalidade infantil, tendo sido muito semelhante à distribuição dos aglomerados do IDHM (pseudo-p $\leq 0,05)$ (Figura 12). 

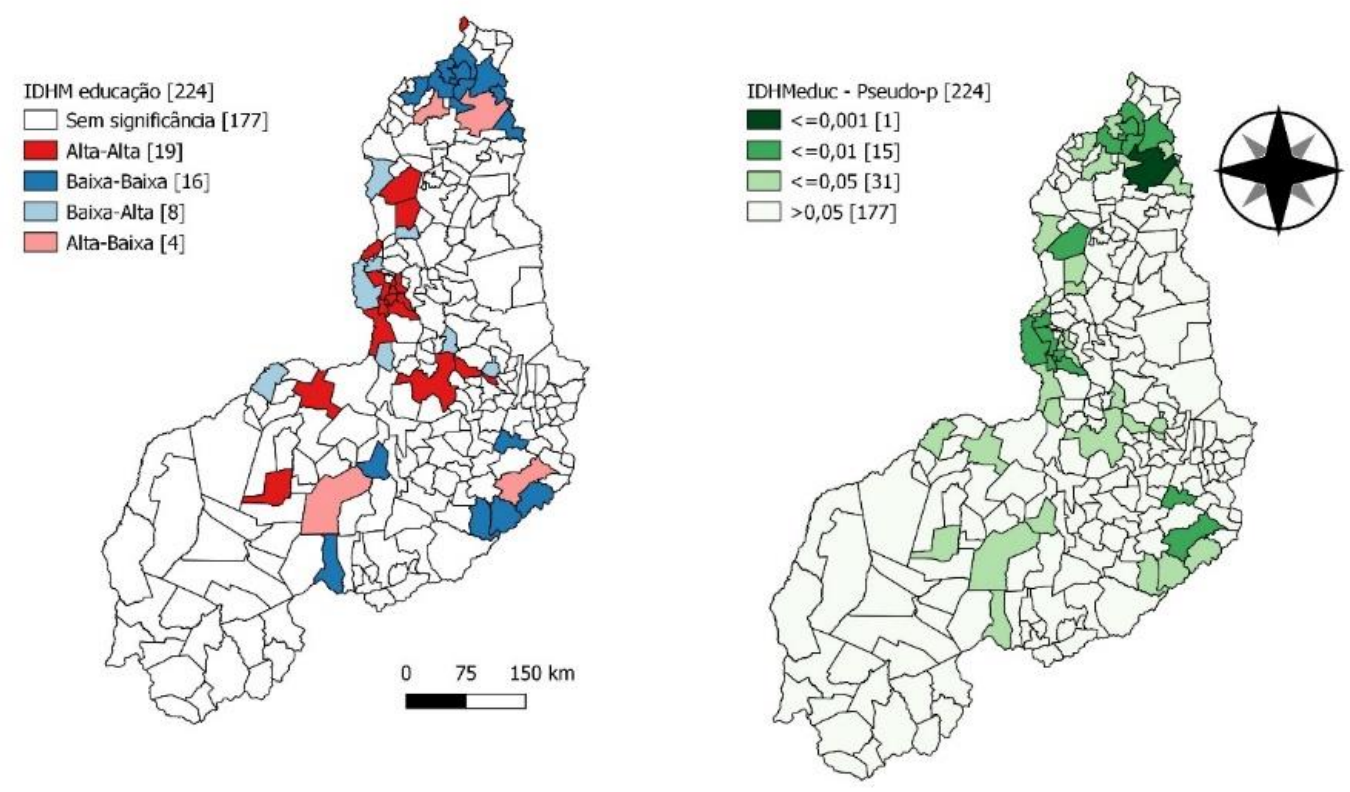

Figura 12. Dependência espacial do componente educação do índice de desenvolvimento humano municipal no Piauí, 2010. Fonte: Atlas Brasil (2020).

Os municípios com maior proporção de pobres tiveram disposição espacial no sudeste e norte do Estado, havendo concordância de áreas de maior risco com os achados espaciais do IDHM e da taxa de mortalidade infantil (pseudo$p \leq 0,05)$ (Figura 13). 

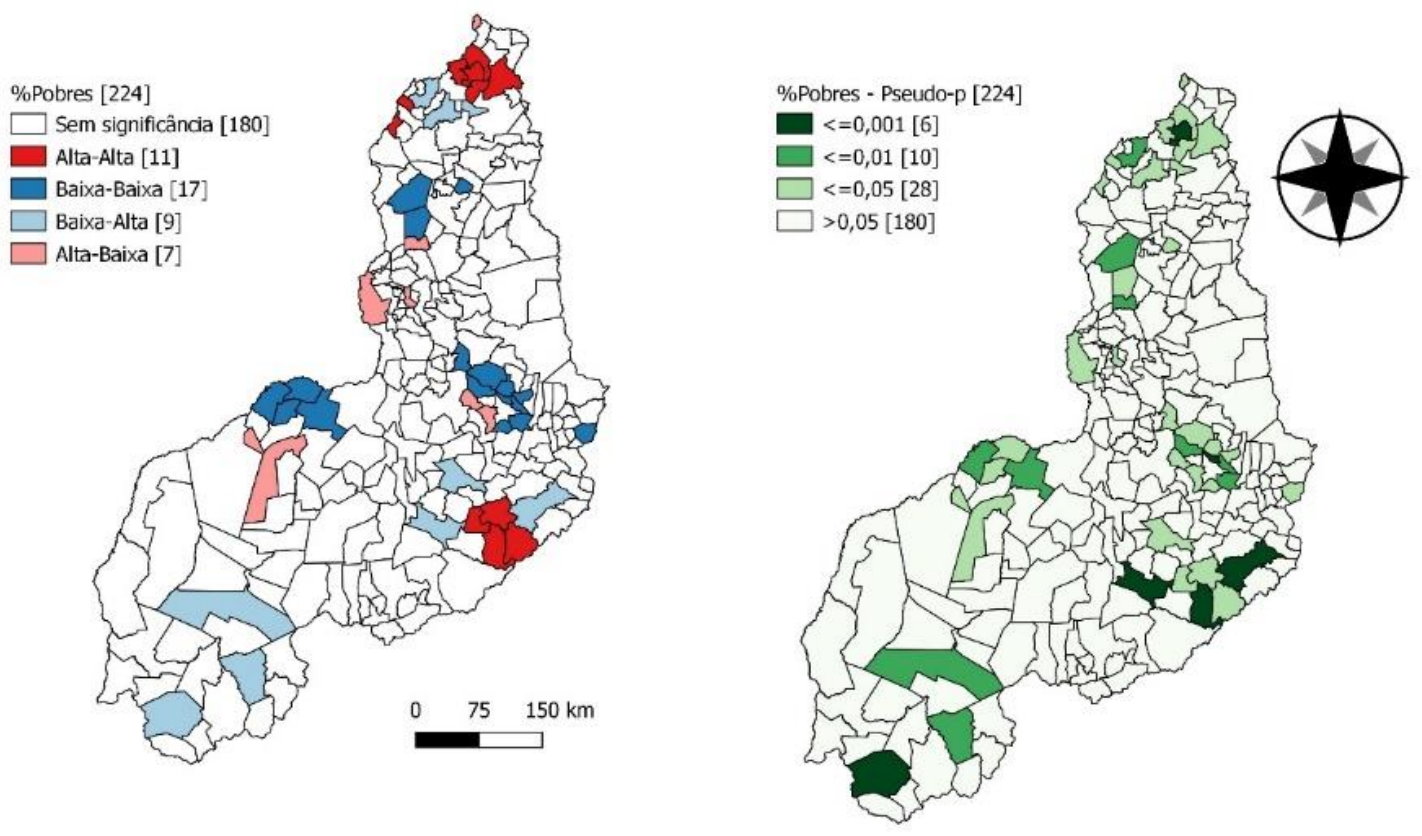

Figura 13. Dependência espacial da proporção de pobres no Piauí, 2010. Fonte: Atlas Brasil (2020).

Somente o IDHM longevidade demonstrou dependência espacial em análise bivariada. $O$ valor I negativo distou $-2,83 \sigma$ à esquerda da média $\mu(I)$, sinalizando formação de dispersões municipais (Tabela 4).

Tabela 4. Dependência espacial bivariada da taxa de mortalidade infantil pelos dos vetores correspondentes aos indicadores. Piauí, 2010. Fonte: Atlas Brasil (2020).

\begin{tabular}{|c|c|c|c|c|c|c|c|c|}
\hline Variável & & & & & Índice & e Mora & Global & \\
\hline Dependente & Explicativa & I & $E[I]$ & $\mu(I)$ & $\sigma(\mathrm{l})$ & $\begin{array}{r}\text { Valor } \\
\mathbf{z}\end{array}$ & $\begin{array}{l}\text { Pseudo } \\
\text { valor-p }\end{array}$ & $\begin{array}{r}\text { local do } \\
\text { índice de } \\
\text { Moran }\end{array}$ \\
\hline Gini & TMI & 0,0189 & 0,0045 & 0,0021 & 0,0308 & $-0,68$ & 0,24 & Não \\
\hline IDHM & TMI & $\begin{array}{r}- \\
0,0521\end{array}$ & $\begin{array}{r}- \\
0,0045\end{array}$ & 0,0027 & 0,0330 & $-1,66$ & 0,06 & Não \\
\hline IDHMlong & TMI & 0,1161 & $\begin{array}{r}- \\
0,0045\end{array}$ & 0,0059 & 0,041 & $-2,97$ & 0,005 & Sim \\
\hline
\end{tabular}




$\begin{array}{lrrrrrrrr}\text { IDHMeduc } & \text { TMI } & -0,048 & - & 0,0021 & 0,0319 & -1,56 & 0,06 & \text { Não } \\ & & & 0,0045 & & & & & \\ \text { \%Pobres } & \text { TMI } & - & - & - & 0,0311 & -0,07 & 0,47 & \text { Não } \\ & & 0,0025 & 0,0045 & 0,0003 & & & & \end{array}$

TMI: taxa de mortalidade infantil; IDHM: índice de desenvolvimento infantil; re: renda e emprego; long: longevidade; educ: educação; \% Pobres: proporção de pobres.

Os outliers correspondentes a alto IDHM longevidade de um município $i$ associando-se com baixa taxa de mortalidade infantil em municípios $j$ (vizinhos) estão sinalizados com cor rosa e concentram-se no noroeste, centro-norte, sudoeste e sul do Estado nos limites com Maranhão e Bahia. Esses municípios foram Altos, Batalha, Beneditinos, Capitão de Campos, Cocal de Telha, Cristalândia do Piauí, Curralinhos, Demerval Lobão, Jatobá do Piauí, José de Freitas, Milton Brandão, Monsenhor Gil, Nazária, Palmeirais, Ribeiro Gonçalves, Sebastião Barros e Teresina (Figura 14).

Os outliers correspondentes a menor IDHM longevidade de um dado município $i$ associado com alta taxa de mortalidade infantil em vizinhos mais próximos situaram-se no sudeste do Estado e estão sinalizados pela cor azul clara. Esses municípios foram Alegrete do Piauí, Belém do Piauí, Betânia do Piauí, Caldeirão Grande do Piauí, Campo Grande do Piauí, Francisco Macedo, Massapê do Piauí, Padre Marcos e Vila Nova do Piauí (Figura 14).
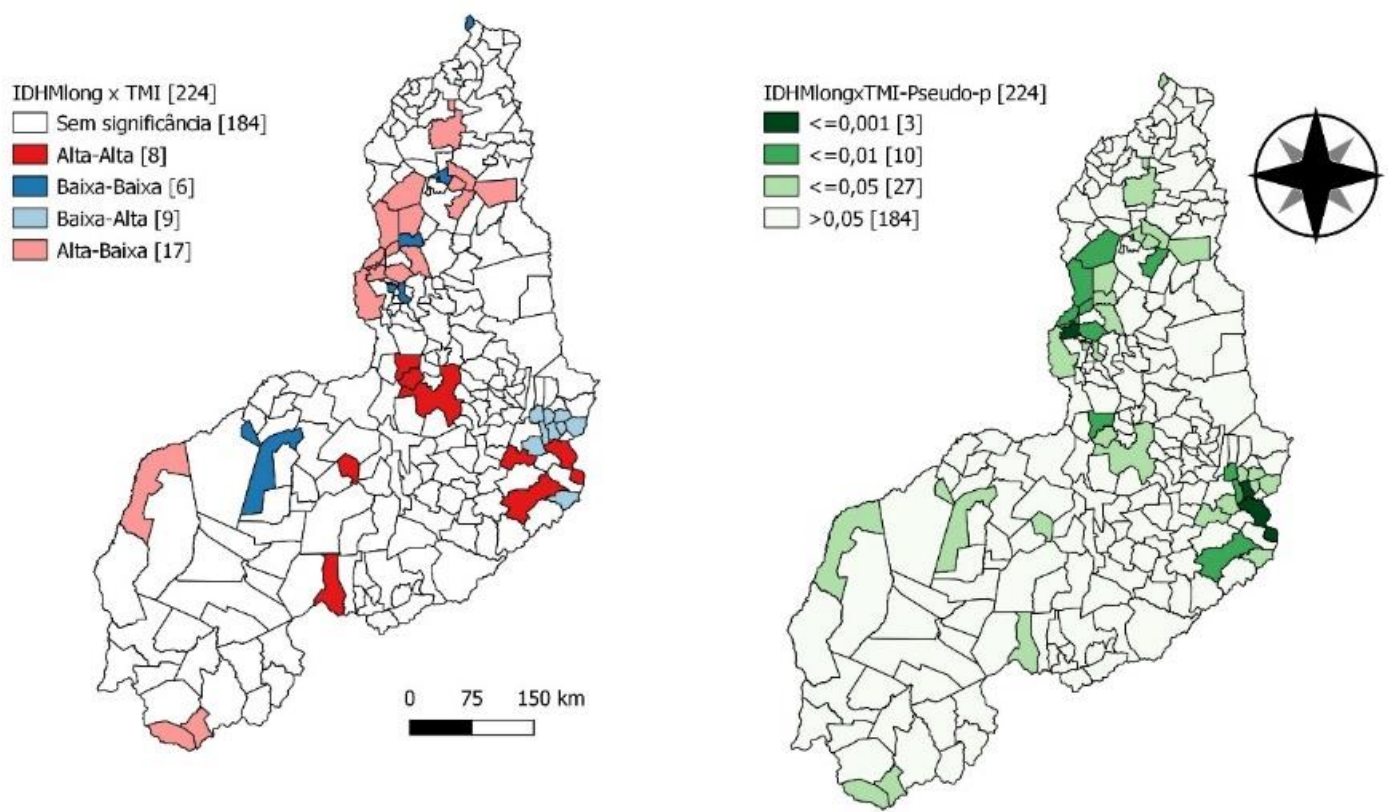
Figura 14. Dependência espacial através de índice de Moran local bivariado entre o componente longevidade do índice de desenvolvimento municipal e a taxa de mortalidade infantil no Piauí, 2010. Fonte: Atlas Brasil (2020).

\section{DISCUSSÃO}

Em 2010, não houve municípios com alta taxa de mortalidade infantil no Piauí. A taxa de mortalidade infantil correlacionou-se de modo complexo e nem sempre homogêneo com o IDHM, com os componentes do IDHM e com a proporção de pobres. Não houve correlação com o coeficiente de Gini.

O IDHM renda e emprego foi o único determinante social que não exibiu dependência espacial. Os municípios situados no noroeste do Estado, onde se situa Teresina, a capital, aglomeraram-se com as menores taxas de mortalidade infantil e proporção de pobres bem como com os maiores valores de IDHM, IDHM longevidade e IDHM educação. Em municípios do sudeste do Estado, ocorreu o inverso.

Em uma análise bivariada de dependência espacial, apenas o IDHM longevidade foi estatisticamente significante. Evidenciaram-se municípios do noroeste do Estado onde maior IDHM longevidade correlacionou-se com menor taxa de mortalidade infantil, enquanto, em municípios do sudeste do Estado, menor IDHM longevidade correlacionou-se com maior taxa de mortalidade infantil.

A taxa de mortalidade infantil em países industrializados e em países da África subsaariana onde existia elevada prevalência de VIH/SIDA em 2000 foi de $6 \%$ e $175 \%$, respectivamente, sinalizando a presença de elementos espacialmente distribuídos vinculados à mortalidade infantil. Naqueles países subsaarianos, existiam graves problemas de desenvolvimento humano, pobreza, baixa renda, educação, menor expectativa de vida, elevados valores do coeficiente de Gini. Estudiosos sobre a situação de saúde nesses países sugerem aumento dos investimentos no setor saúde, melhoramento dos processos no setor saúde e das condições que definem o desenvolvimento humano quais sejam as condições ambientais, a acessibilidade aos serviços de saúde e condições de moradia dignas, educação de qualidade, alimentação, trabalho, cuidados prénatais, medicina preventiva e garantia de direitos humanos ${ }^{14}$.

As relações entre os determinantes sociais com a mortalidade infantil são complexas. A intensidade da associação, presença ou ausência de associação e relação direta ou inversa varia bastante entre localidades e com o tipo de análise. Na África do Sul, em modelos univariados, o coeficiente de Gini está associado com um maior risco de óbito infantil em 2007. No modelo multivariado espacial, no entanto, o coeficiente de Gini não foi fator de risco independente para a ocorrência de óbitos infantis ${ }^{14}$.

Países árabes na África e na Ásia, em 2002, estiveram da $40^{\underline{a}}$ a $152^{a}$ posição quanto ao IDHM e a taxa de mortalidade infantil variou de oito a $133 \%$. De modo que nos países árabes mais pobres, não produtores de petróleo e com 
problemas de saúde ambiental e, por conseguinte, menores valores do IDHM houve maior mortalidade infantil, enquanto países árabes produtores de petróleo onde existem melhores condições de urbanização, maior valor do IDHM e menor população e maior acessibilidade à educação e à saúde, houve menor taxa de mortalidade infantil ${ }^{28}$.

Em um estudo sobre a relação entre a taxa de mortalidade infantil e IDHM, coeficiente de Gini e taxa de pobreza nos municípios do Estado do Paraná em 2010 , o valor máximo da taxa de mortalidade infantil foi $61,22 \%$, tendo estado 222 de 399 municípios abaixo da média (12,71\%o). O Paraná possuía em 2010 $59,64 \%$ dos municípios abaixo da média da taxa de pobreza $(10,27 \%), 43,36 \%$ dos municípios com IDHM abaixo da média estadual $(0,702)$ e 50,88\% dos municípios acima da média do coeficiente de Gini. Lá houve concordância espacial na distribuição dos municípios com elevado coeficiente de Gini, com elevada taxa de pobreza e menores taxas do IDHM. A análise local do índice de Moran bivariado permitiu reconhecer agrupamentos de municípios muito parecidos para as três autocorrelações espaciais correspondentes aos três determinantes sociais com a taxa de mortalidade infantil ${ }^{3}$.

Estudo de análise espacial da taxa de mortalidade infantil no Ceará afirmou que a intervenção sobre a taxa de mortalidade infantil desloca-se tendenciosamente para a esfera dos serviços de saúde, em particular, médico assistenciais, porém, a acessibilidade à saneamento básico e à educação têm o potencial de homogeneizar as taxas de mortalidade infantil a dependência espacial da taxa de mortalidade infantil ${ }^{29}$. Isto indica que a ausência de dependência espacial em análises univariadas ou bivariadas podem significar condições de vida e acessibilidade aos serviços básicos homogeneamente bons ou ruins.

As limitações deste estudo consistem na falácia ecológica, porquanto correlação ecológica e inferências causais do efeito ecológico não necessariamente refletem o efeito biológico do nível individual ${ }^{29}$. Além disso, utilizou-se um vetor de taxa de mortalidade infantil informado pelo Atlas de Desenvolvimento Humano no Brasil o qual diverge do cálculo bruto a partir de vetores em separado do número de óbitos em menores de um ano de vida e o número de nascidos vivos em 2010 a partir do TABNET DATASUS.

Perspectivas futuras são o confrontamento de métodos espaciais bayesianos com métodos estatísticos frequentista como os que foram utilizados neste trabalho, porquanto trabalhar com probabilidade suavizada pelo fator espacial poderá aproximar os achados dos fenômenos ecológicos reais ${ }^{30}$. Estudos que estratifiquem a taxa de mortalidade em seus componentes neonatal precoce, neonatal tardio e pós-neonatal, bem como estratificação segundo o diagnóstico e condições socioeconômicas da genitora poderão dispor de informações úteis para o planejamento estratégico em saúde materno-infantil e de gestão pública ${ }^{29}$, visando melhores condições de vida da população residente nos municípios piauienses.

\section{CONCLUSÕES}


Este trabalho identificou correlação e dependência espacial entre a taxa de mortalidade infantil e determinantes sociais. A ausência de correlação ou dependência espacial não significou ausência de associação entre a mortalidade infantil e o dado determinante social. A associação pode ser complexa a ponto de não ficar evidente a uma só técnica estatística, sendo necessários vários métodos para tornar evidente relação entre as variáveis.

A análise espacial permitiu identificar localidades de maior risco de óbito infantil associados com piores condições de vida. Essas áreas são alvos potenciais de trabalho em Administração em Saúde e em Medicina Preventiva e Social.

\section{REFERÊNCIAS}

1. BRASIL. Indicadores básicos para a saúde no Brasil: conceitos e aplicações. 2a ed. Brasília: Organização Pan-Americana da Saúde; 2008.

2. Filho JGB, Kerr LRFS, Miná D de L, Barreto ML. Distribuição espacial da taxa de mortalidade infantil e principais determinantes no Ceará, Brasil, no período 2000-2002. Cad Saude Publica. 2007; 23(5):1173-1185. https://doi.org/10.1590/s0102-311x2007000500019

3. Marcello T, Cavalari IA, Carvalho M, et al. Análise espacial da taxa de mortalidade infantil no Paraná. Brazilian J Dev. 2019; 5(10):1886218876. https://doi.org/10.34117/bjdv5n10-127.

4. Ortega E, Ochoa C. Estudios ecológicos en Epidemiología. Evidências en Pediatría. 2015; 11(69):1-5.

5. Medronho R de A, Bloch KV, Luiz RR, Werneck GL. Epidemiologia. 2a ed. São Paulo: Editora Atheneu; 2009.

6. Nogueira RP, org. Determinação social da saúde e Reforma Sanitária. 1a ed. Rio de Janeiro: CEBES; 2010.

7. Netto GF, Freitas CM de, Andahur JP, Pedroso M de M, Rohlfs DB. Impactos socioambientais na situação de saúde da população brasileira: Estudo de indicadores relacionados ao saneamento ambiental inadequado. Tempus Actas em Saúde Coletiva. 2009; 4(4):53-71.

8. Folland S, Goodman AC, Stano M. The Economics of Health and Health Care. 8a ed. New York, NY: Routledge; 2017. https://doi.org/10.4324/9781315103488

9. World Health Organization. Environmental Health Indicators for Europe: A Pilot Indicator-Based Report. Copenhagen: WHO Regional Office for Europe; 2004.

10. Costa DR, Rego AGS, Lima DSN. Geografia médica da mortalidade cardiovascular no Piauí: uma ciência a serviço da administração em 
saúde. Rev Adm Saúde. 2019; 19(75).

https://doi.org/10.23973/ras.75.172

11. Rodrigues M, Bonfim C, Portugal JL, et al. Análise espacial da mortalidade infantil e adequação das informações vitais: uma proposta para definição de áreas prioritárias. Ciên Saúde Colet. 2014; 19(7):2047-2054. https://doi.org/10.1590/1413-81232014197.18012013

12. Guimarães RB. Geografia e saúde coletiva no Brasil. Saúde e Soc. 2016; 25(4):869-879. https://doi.org/10.1590/s0104-12902016167769

13. De Paiva SMA, Silveira CA, Gomes ELR, Tessuto MC, Sartori NR. Teorias administrativas na saúde. Rev Enferm. 2010; 311-316.

14. Sartorius BKD, Sartorius K, Chirwa TF, Fonn S. Infant mortality in South Africa - distribution, associations and policy implications, 2007: an ecological spatial analysis. Int J Health Geogr. 2011; 10(61). https://doi.org/10.1186/1476-072X-10-61

15. Kolb RW. Gini Index. In: The SAGE Encyclopedia of Business Ethics and Society. 2455 Teller Road, Thousand Oaks, California 91320: SAGE Publications, Inc.; 2018. https://doi.org/10.4135/9781483381503.n521

16. Shaw M, Galobardes B, Lawlor DA, Lynch J, Wheeler B, Smith GD. Gini coefficient. In: The handbook of inequality and socioeconomic position. Bristol University Press; 2017:157-159. https://doi.org/10.2307/j.ctt1t892cc.59

17. Programa das Nacões Unidas para o Desenvolvimento. Consulta | Atlas do Desenvolvimento Humano no Brasil 2013. Atlas do Desenvolvimento Humano Brasil. http://www.atlasbrasil.org.br/2013/pt/consulta/. Published 2013. Acessado abril 27, 2020.

18. Lind N. Human Development Index (HDI). In: Encyclopedia of Quality of Life and Well-Being Research. Dordrecht: Springer Netherlands; 2014. p. 3012-3013. https://doi.org/10.1007/978-94-007-0753-5 1342

19. Morse S. Human Development Index. In: The Rise and Rise of Indicators. Abingdon, Oxon; New York, NY: Routledge, 2019.: Routledge; 2019. p. 61-81. https://doi.org/10.4324/9781315226675-3

20. Owen A. Spearman's correlation coefficien. STATSTUTOR. http://www.statstutor.ac.uk/types/tests-and-quizzes/spearmanscorrelation-coefficient/. Published 2020. Acessado abril 27, 2020.

21. Oyana TJ, Margai FM. Spatial Analysis: statistics, visualization, and computational methods. 1a ed. Boca Raton: CRC Press; 2016.

22. McLeod Al, Yu H, Mahdi E. Time Series Analysis with R. In: Handbook of Statistics; 2012. p. 661-712. https://doi.org/10.1016/B978-0-444-53858$\underline{1.00023-5}$ 
23. Crawley MJ. The R Book. Chichester, UK: John Wiley \& Sons, Ltd; 2007. https://doi.org/10.1002/9780470515075

24. Almeida E. Economia Espacial Aplicada. 1a ed (Silva FD da, Lima T, orgs.). Campinas: Editora Alinea; 2012.

25. Anselin L. Local Indicators of Spatial Association-LISA. Geogr Anal. 2010; 27(2):93-115. https://doi.org/10.1111/j.1538-4632.1995.tb00338.x

26. Anselin L. Global Spatial Autocorrelation (1): Moran Scatter Plot and Spatial Correlogram. GeoDa: An Introduction to Spatial Analysis. https://geodacenter.github.io/workbook/5a global auto/lab5a.html. Published 2018. Acessado agosto 12, 2019.

27. Marcello T, Cavalari IA. Análise espacial da taxa de mortalidade infantil no Paraná. Brazilian J Dev. 2019; 5(10):127. https://doi.org/10.34117/bjdv5n10-127

28. Boutayeb A, Serghini M. Health indicators and human development in the Arab region. Int J Health Geogr. 2006; 5(61):1-13. https://doi.org/10.1186/1476-072X-5-61

29. Filho JGB, Kerr LRFS, Miná DDL, Barreto ML. Distribuição espacial da taxa de mortalidade infantil e principais determinantes no Ceará, Brasil, no período 2000-2002. Cad Saude Publica. 2007; 23(5):1173-1185. https://doi.org/10.1590/S0102-311X2007000500019

30. Alexander N. Bayesian Disease Mapping: Hierarchical Modeling in Spatial Epidemiology. J R Stat Soc, Series A. 2011; 174(2):512-513. https://doi.org/10.1111/j.1467-985X.2010.00681 11.x

Recebido: 28 de abril de 2020. Aceito: 30 de setembro de 2020

Correspondência: Djalma Ribeiro Costa. E-mail: djalmacosta1@gmail.com

Conflito de Interesses: os autores declararam não haver conflito de interesses.

(C) This is an Open Access article distributed under the terms of the Creative Commons Attribution License, which permits unrestricted use, distribution, and reproduction in any medium, provided the original work is properly cited 